\title{
Risk for and consequences of endometriosis: a critical epidemiologic review
}

Shafrir AL,${ }^{1,2, *}$ Farland LV, ${ }^{3,4, *}$ Shah DK, ${ }^{5}$ Harris HR, ${ }^{6}$ Kvaskoff M, ${ }^{7,8}$ Zondervan $\mathrm{K},{ }^{9,10}$ Missmer $\mathrm{SA}^{1,2,4,11}$

1. Division of Adolescent and Young Adult Medicine, Department of Medicine, Boston Children's Hospital and Harvard Medical School, Boston, MA, USA

2. Boston Center for Endometriosis, Boston Children's and Brigham and Women's Hospitals, Boston, MA, USA

3. Department of Obstetrics, Gynecology, and Reproductive Biology, Brigham and Women's Hospital and Harvard Medical School, Boston, MA, USA

4. Department of Epidemiology, Harvard T.H. Chan School of Public Health, Boston, MA, USA

5. Department of Obstetrics and Gynecology, University of Pennsylvania, Philadelphia, PA, USA

6. Program in Epidemiology, Division of Public Health Sciences, Fred Hutchinson Cancer Research Center, Seattle, WA, USA

7. CESP, Fac. de médecine - Univ. Paris-Sud, Fac. de médecine - UVSQ, INSERM, Université Paris-Saclay, Villejuif Cedex, France.

8. Gustave Roussy, Espace Maurice Tubiana, Villejuif Cedex, France

9. Wellcome Trust Centre for Human Genetics, University of Oxford, Oxford OX3 7BN, UK

10. Endometriosis CaRe Centre, Nuffield Dept of Obstetrics \& Gynaecology, University of Oxford, John Radcliffe Hospital, Oxford OX3 9DU, UK

11. Department of Obstetrics, Gynecology, and Reproductive Biology, College of Human

Medicine, Michigan State University, Grand Rapids, MI, USA

*Contributed equally as first authors.

Corresponding author and to whom requests for reprints should be made:

Amy L. Shafrir

Boston Children's Hospital

1 Autumn Street, $5^{\text {th }}$ Floor

Boston, MA 02115

Email: amy.shafrir@childrens.harvard.edu

Phone: 617-355-4127

Word Count: 5,167 in text and figures, 8,511 in text, figures and references 


\begin{abstract}
Word count: 125

Endometriosis affects approximately $10 \%$ of reproductive aged women. Characteristics that have been robustly associated with endometriosis include earlier age at menarche, shorter menstrual cycle length, and leaner body size associated with greater risk, while greater parity has been associated with lower risk. Relationships with other potential characteristics, including physical activity, dietary factors, and lactation, have been less consistent, partially due to the need for rigorous data collection and longitudinal study design. Critical methodologic complexities include the need for a clear case definition, valid selection of comparison/control groups, and consideration of diagnostic bias and reverse causation when exploring demographic characteristics, medical history, and lifestyle factors. Reviewers and editors must demand detailed description of rigorous methods to facilitate comparison and replication to advance our understanding of endometriosis.
\end{abstract}

Keywords: endometriosis, epidemiology, study design, incidence, risk factors, co-morbidities 


\section{Endometriosis Prevalence and Incidence}

Accurate measurement of the incidence and prevalence of endometriosis is complicated by the current requirement for surgical visualization to establish a definitive diagnosis. Factors influencing referral for / acceptance of surgery and access to surgical expertise create a biased sample among those who achieve a diagnosis. Prevalence estimates vary considerably among different populations, ranging from approximately $2-4 \%$ among asymptomatic women seeking tubal ligation [1-3] to 5-50\% among infertile women [4-8] and 5-21\% among women hospitalized for pelvic pain [4-8]. However, the actual prevalence of endometriosis is likely underestimated among women undergoing an elective tubal ligation, and, conversely, is likely overestimated among women undergoing surgery/hospitalization for pain symptoms and/or infertility. Most recently, the ENDO study enrolled 495 women undergoing laparoscopy/laparotomy between 2007 and 2009 and 131 women from the general population to estimate the incidence of endometriosis. Approximately $41 \%$ of women scheduled to undergo laparoscopy were found to have surgically-visualized endometriosis compared with approximately $11 \%$ of women from the general population visually diagnosed using magnetic resonance imaging [9].

Based on prevalence estimates of pelvic pain and subfertility in the general population, the estimated overall prevalence of endometriosis is $10 \%$, and approximately $2 \%$ for undiagnosed symptomatic disease [10]. Few studies have investigated endometriosis incidence and prevalence among adolescents. The reported prevalence of visually-confirmed endometriosis among adolescents with pelvic pain ranges from $25-100 \%$, with an average of $49 \%$ among 
adolescents with chronic pelvic pain and $75 \%$ among adolescents unresponsive to medical treatment [11].

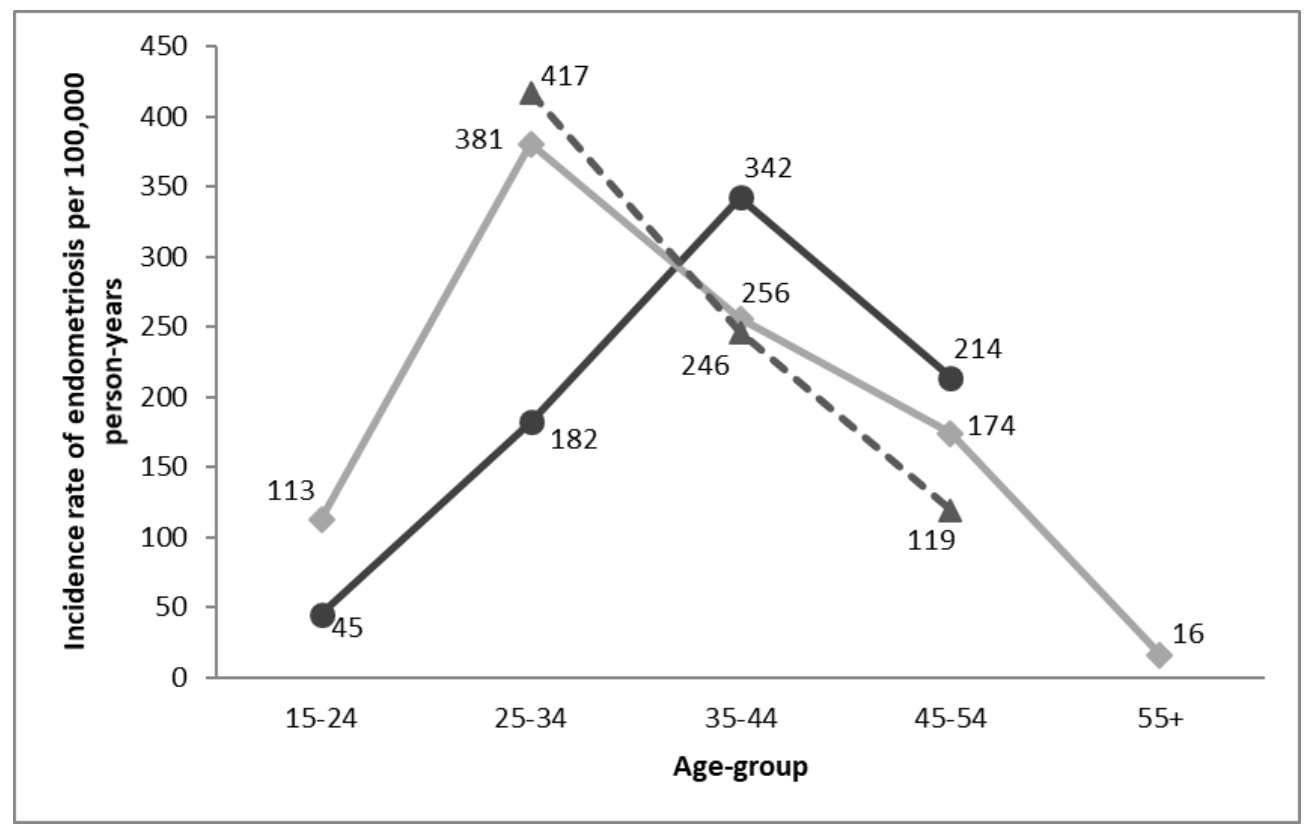

Figure 1: Age-specific incidence rates of endometriosis among women in Rochester, Minnesota and across the US. The darker solid line with circles is adapted from Houston et al. [12] and is based on histologically-confirmed endometriosis during the 1970s. The lighter solid line with diamonds is adapted from Leibson et al [13] and is based on clinically diagnosed endometriosis during the 1990s. The dashed line with triangles is adapted from Missmer et al. [14] and is based on surgically-confirmed endometriosis in the 1990s.

Information on the incidence of endometriosis in the general population is limited. Two studies have reported the age-specific incidence of endometriosis diagnosis among white women in Rochester, Minnesota (Figure 1). Houston et al. [12] reported an overall incidence of histologically-confirmed endometriosis of 160.4/100,000 person-years among women aged 1549 years between 1970 and 1979, with a peak between ages 35-44 years (342.3/100,000 personyears). In this same geographic region, Leibson et al. [13] observed an overall incidence rate of clinically diagnosed endometriosis of 187/100,000 person-years among women aged $>15$ years from 1987 to 1999, with a peak in incidence between ages 25-34 years (380.6/100,000 person- 
years). Similar incidence patterns to Leibson et al. [13] were observed in the Nurses' Health

Study II (NHSII) (Figure 1). The NHSII is a prospective cohort of 116,429 U.S. female nurses aged 25-42 at enrollment in 1989. Between 1989 and 1999, the incidence rate of laparoscopically-confirmed endometriosis was 298/100,000 person-years [14]. While the incidence peaked at ages 25-34 (417/100,000 person-years), the decrease in incidence was more modest for women without a history of infertility, declining only after age 44 years (ptrend<0.0001) [14].

\section{Methodologic Issues in Endometriosis-focused Study Design}

The key methodologic issues for endometriosis discovery - whether clinical, population, or bench science - include choosing a valid (1) endometriosis case definition and (2) comparison group, and (3) defining the appropriate etiologic window to capture the exposures, outcomes, and disease progression to address the study aims [10,15-17]. In general, case-control studies of endometriosis tend to be more vulnerable to bias due to control selection and recall; however, these issues can occur in all study designs.

\section{Endometriosis Case Definition}

There are multiple pathways through which a person with endometriosis may be diagnosed or mis/un-diagnosed (Figure 2). Some women are diagnosed due to pelvic pain, while others are diagnosed at the time of an infertility evaluation or diagnosed incidentally for unrelated pelvic surgical procedures (such as appendectomy or tubal ligation). The wide variation in both symptoms, surgically visualized presentation and pathologic findings makes selection of an appropriate case definition for endometriosis both critical and challenging. 


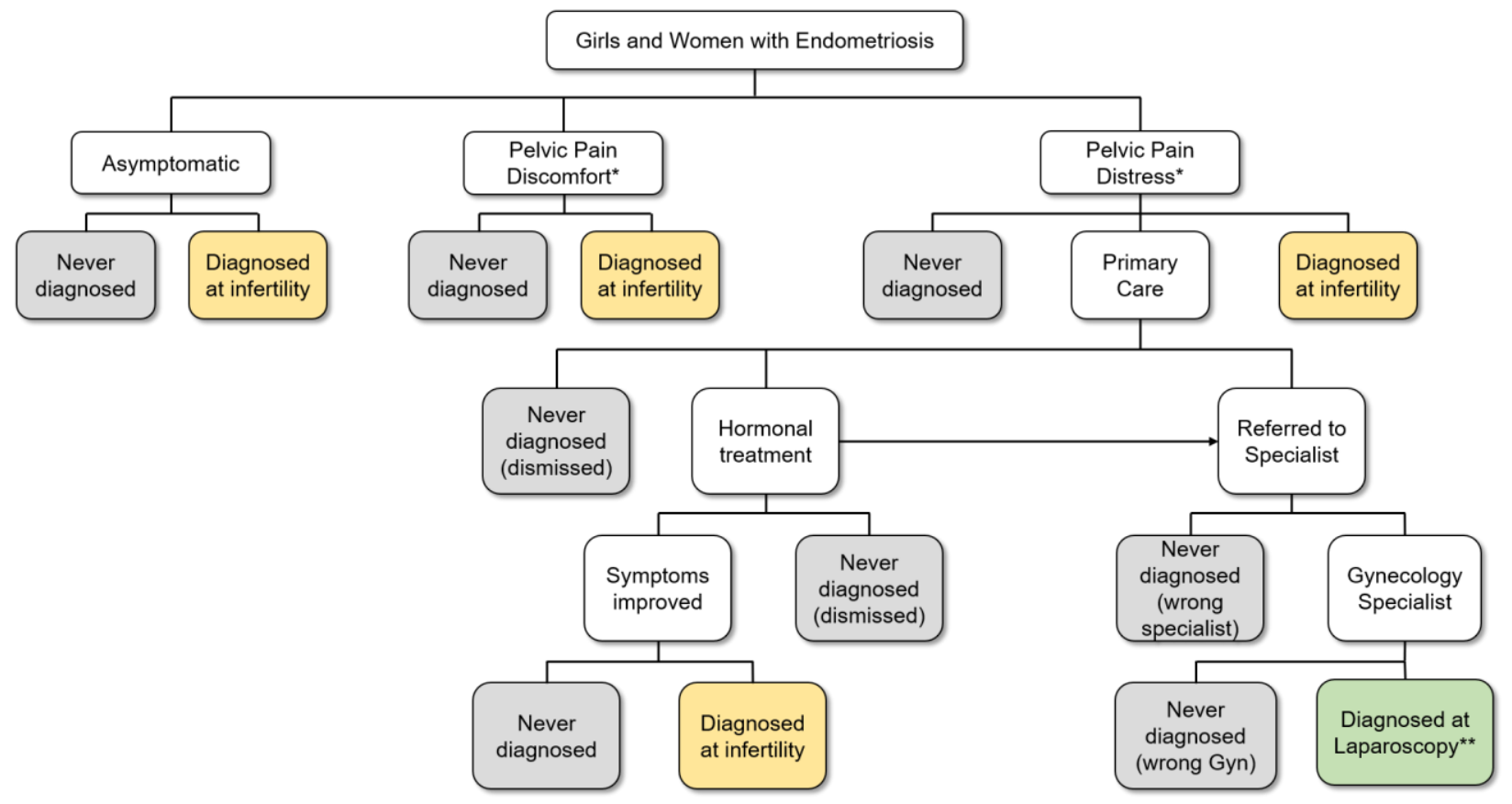

Figure 2. Pathways to surgical endometriosis diagnosis. Given the current requirement for surgical visualization for a definitive diagnosis, women can reach a surgical diagnosis of endometriosis through multiple pathways including through laparoscopy for an infertility evaluation (yellow boxes) or due to pain symptoms (green box). Women with endometriosis may also never reach a surgical diagnosis (gray boxes).

*Pelvic pain discomfort and pelvic pain distress terminology attributed to Deborah Bush of Endometriosis New Zealand. Discomfort categorizes pelvic pain considered to be "normal," or of too low impact to warrant referral for surgical evaluation.

**Endometriomas and deep endometriosis may also be diagnosed through radiologic methods. Any of these paths could include sporadic incidental diagnoses during other surgeries such as appendectomy, cholecystectomy, or tubal ligation.

Laparoscopy remains the gold standard for diagnosing endometriosis $[18,19]$. The accuracy of self-reported endometriosis varies among populations $[14,20]$. However, women who undergo laparoscopy for a definitive diagnosis due to pain symptoms may differ in pathophysiology, symptomatology, and risk factor profiles from (1) women whose symptoms are managed less invasively through anti-inflammatory treatments or oral contraceptives (OCs) and from (2) women with 'asymptomatic' endometriosis identified through infertility evaluation or incidental visualization. These differences may introduce selection bias when surgical confirmation is used 
as a case definition, as those who have access to laparoscopy may be more frequent users of the medical system or have more severe symptoms compared with women who do not undergo a laparoscopy. This issue of selection bias is particularly important for "adolescent" endometriosis given that only those with the most severe symptoms will undergo surgery. Similarly, studies that only include women whose endometriosis was diagnosed as part of an infertility evaluation may under-sample women with pelvic pain [21], as these women may never have come to laparoscopic diagnosis if they had not attempted pregnancy and if they did not have access to an infertility evaluation [22,23].

Thus, various endometriosis case definitions can be considered including diagnosis based on symptoms, laparoscopic confirmation due to pelvic pain, infertility or unrelated surgery, or visualization through imaging techniques. Surgically evaluated cases can be further subdivided based on the revised American Society for Reproductive Medicine (rASRM) disease staging system. However, it is important to note that rASRM stage does not correlate with endometriosis symptoms nor with prognosis [24]. While many case definitions are valid given the aims of a study, clear reporting of the chosen endometriosis case definition [25] in published studies is extremely important for interpretation, comparison, and validation of study findings.

\section{Comparison / control group}

A similar challenge in endometriosis research exists when attempting to define a valid comparison group. This is of particular importance in case-control studies, as controls must represent the exposure distribution of the population that gave rise to the cases, and sampling 
must be independent of the exposure. Strategies for control selection will depend on the hypothesis to be tested. Often women undergoing pelvic surgery for reasons other than endometriosis (e.g. tubal ligation, hysterectomy, or laparoscopy) are included as the control group in an effort to prevent the inclusion of undiagnosed cases among the controls. However, these highly selected women represent a biased sample of those from the underlying population, e.g. tubal ligation controls are multiparous and not a valid control for case women diagnosed during an infertility evaluation [10] (Figure 3). Additionally, inclusion of controls undergoing surgery for a pathology other than endometriosis may lead to an erroneously null association if the pathology is related to the exposure of interest, for example environmental toxin exposure or body size.

\section{Ideal situation}

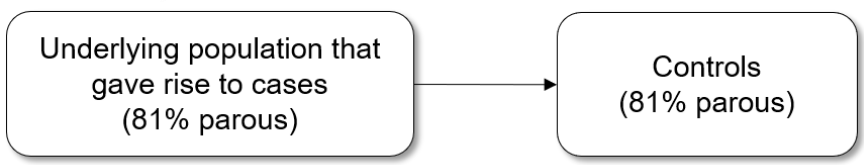

Controls selected from women with tubal ligation

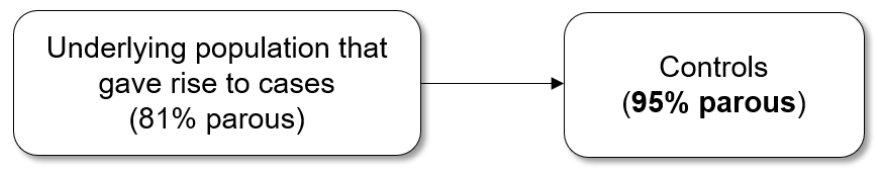

Figure 3. Potential for selection bias in case-control studies of endometriosis. Selection bias may arise when utilizing women undergoing tubal ligation as the control group in a case-control study. This is an example of bias introduced if parity is related to the exposure under study (e.g. body size, breastfeeding duration, miRNA profile, or epigenetic profile). Numbers are based on data from the NHSII.

Fertility status also presents a challenge in studies of endometriosis as women who seek a medical evaluation for infertility differ on important demographic, lifestyle, and access to healthcare factors from infertile women who do not access these services. Failure to account for 
these differences may lead to selection bias or hinder generalizability [22], particularly when exposures of interest, such as menstrual cycle characteristics, body size, or hormonal milieu, are correlated with both endometriosis and infertility.

\section{Onset of Endometriosis Symptoms}

To understand the relationship with modifiable risk factors, epidemiologic studies should ideally focus on incident rather than prevalent cases of disease. However, the exact time of disease onset is unknown for endometriosis, as a symptom "threshold" must typically be reached before evaluation is sought. In the case of endometriosis, the literature reports delays averaging sevenyears from symptom onset to surgical diagnosis [21]. As a result, most epidemiologic investigations are estimating the incidence of endometriosis diagnosis as opposed to the true disease onset. The temporal relationship between exposure and disease must therefore be interpreted critically when considering modifiable risk factors or biomarkers that are interpreted as having a role in disease etiology but may actually change as a consequence of endometriosis symptoms - resulting in reverse causation (Figure 4). 


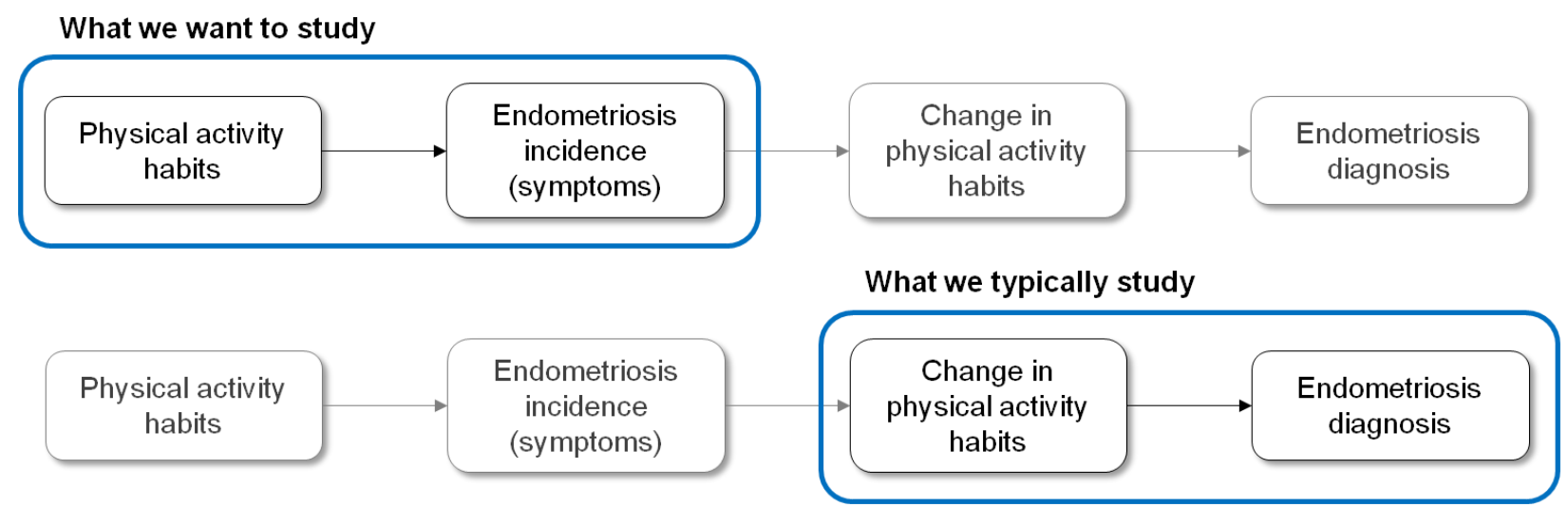

Figure 4. Example of potential for reverse causation in epidemiologic studies. If endometriosis symptoms have an impact on physical activity habits, then analyses of physical activity and prevalent endometriosis will typically be assessing this changed physical activity level in relation to endometriosis diagnosis as opposed to physical activity levels before symptoms and the true incidence of endometriosis.

Taking into account these various methodologic challenges, we now present a review of the current discoveries regarding risk factors for endometriosis (Figure 5).

\section{Endometriosis Risk Factors}

\section{In-Utero and Early Life Exposures}

Maternal exposure to environmental toxins: Prenatal exposure to diethylstilbestrol (DES), a synthetic estrogen, has been associated with a greater risk of endometriosis in the NHSII cohort (Rate Ratio $[\mathrm{RR}]=1.8,95 \% \mathrm{CI}=1.2-2.8$ ) [26] and also the suggestion of greater risk in a population-based case-control study in western Washington State (Odds Ratio [OR]=1.3, 95\% $\mathrm{CI}=0.5-3.6)$ [27]. In-utero DES exposure, which has been linked to reproductive tract structural abnormalities and altered estrogen receptor expression, potentially influences endometriosis development through increased retrograde menstruation and immune dysfunction [26,28]. 
Exposure to paternal cigarette use during gestation has been associated with a non-significant reduction in the odds of endometriosis within the ENDO study ( $\mathrm{OR}=0.72 ; 95 \% \mathrm{CI}=0.43-1.19)$ [29]. An even stronger and statistically significant reduction in the odds of endometriosis $(\mathrm{OR}=0.22 ; 95 \% \mathrm{CI}=0.06-0.82)$ was observed for self-reported prenatal cigarette exposure in a small prospective hospital-based study [30]. As current smoking appears to decrease circulating estrogen levels among women [31], these results suggest that exposure to cigarette smoke during gestation may alter circulating maternal hormone levels, highlighting the potential importance of the maternal hormonal milieu in endometriosis etiology.

Birth characteristics: While few studies have assessed birth weight and endometriosis risk, the current evidence suggests a higher risk among women born at lower birth weights compared to normal or high birth weights [26,29,32]. Compared to having a normal birth weight (defined as 7.0-8.4 pounds), women in the NHSII cohort born at lower birth weights ( $<5.5$ pounds) had a significant greater risk of developing endometriosis later in life ( $\mathrm{RR}=1.3,95 \% \mathrm{CI}=1.0-1.8)$ [26]. Differences in birth weight may reflect variations in the hormonal milieu within the in utero environment or in the adequacy of blood supply to the fetus during pregnancy. Conversely, conflicting results have been observed for the association between prematurity and endometriosis risk with some studies reporting a greater risk $[27,32]$ and others reporting no association [26,29]. It is critical for valid interpretation for studies on birth weight to restrict analyses to fullterm births only, and for studies of prematurity to adjust for birth weight. Lack of rigorous statistical analysis may underlie the inconsistent findings. 


\section{Childhood and Adolescent Exposures}

Menstrual cycle characteristics: Earlier age at menarche has been consistently associated with an higher risk of endometriosis [33-35], potentially through an altered hormonal environment or earlier and increased duration of exposure to retrograde menstruation. A recent meta-analysis of 10 case-control studies calculated that endometriosis cases were 0.15 standard deviations of age (in years) younger at time of first menstrual period than controls [35]. Additionally, within the NHSII cohort shorter menstrual cycles ( $<26$ days) during late adolescence (18-22 years) were associated with an greater rate of endometriosis compared to 26-31 day menstrual cycles [33].

Body size: The current evidence suggests an inverse association between childhood and adolescent body size and the risk of endometriosis [36-40]. In a recent nested case-control study within the French E3N cohort, 61,208 women estimated their childhood body size using Sorensen somatotypes [41]. Women reporting large compared to lean body sizes at 8 years old and at menarche had lower odds of endometriosis $(\mathrm{OR}=0.86,95 \% \mathrm{CI}=0.77-0.95$ and $\mathrm{OR}=0.79$, 95\% $\mathrm{CI}=0.71-0.88$, respectively) [39]. A similar inverse association between childhood body size and endometriosis risk was observed in the NHSII (p-trend=0.0002), and this association was independent of age at menarche and adulthood body mass index (BMI) [38]. Among endometriosis cases, a Korean hospital-based study observed that cases with smaller childhood body size were more likely to present with rASRM disease stages III/IV compared to stages I/II (p-trend=0.002) [42]. 
Additionally, adult height may be a surrogate for childhood exposure to growth factors. Both the NHSII cohort study and the nested case-control study within E3N noted that taller adult height was associated with a higher likelihood of endometriosis compared to shorter adult height $[14,39,40]$. Additionally, three case-control studies have reported greater odds of endometriosis with taller height $[37,43,44]$.

Other Early Life Exposures: Exposure during childhood/adolescence to indoor passive smoke for several hours per day, higher physical activity proximal to menarche, and more severe or frequent sunburns during childhood/adolescence have all been associated with higher risk of endometriosis but warrant replication and additional investigation [45-47].

\section{Adulthood Exposures}

Menstrual cycle characteristics: Shorter menstrual cycles during adulthood have been consistently associated with greater endometriosis risk [33,34,44]. Less consistent evidence has accumulated relating to monthly duration of menses, regularity of menstrual cycles, heaviness of menstrual flow, and tampon use [34,44,48].

Pregnancy and lactation: While pregnancy may be important in endometriosis etiology, it is also an important detection window for endometriosis, particularly among asymptomatic women presenting with infertility, thus rendering the evaluation of associations between pregnancy and endometriosis challenging methodologically. An inverse association between parity and 
endometriosis was reported in three case-control studies [49-51] and in one cohort study regardless of time since last birth [33]. Importantly, while women with endometriosis in the NHSII cohort were found to have a two-fold higher risk of incident infertility, $83 \%$ of nurses with endometriosis were parous by the age of 40 [52]. Similar findings were reported in the ENDO study [53].

A recent analysis in the NHSII noted a lower risk of endometriosis with longer length of total breastfeeding $(\mathrm{RR}=0.92,95 \% \mathrm{CI}=0.90-0.94$ for every additional 3 months of breastfeeding per pregnancy) and an even stronger inverse association for exclusive breastfeeding ( $R R=0.86 ; 95 \%$ $\mathrm{CI}=0.81-0.90)[54]$. This association was partially attributed to the length of postpartum amenorrhea. Pregnancy and lactation result in hormonal changes, including increased levels of progesterone and prolactin, respectively, which may hinder implantation and/or growth of endometrial lesions. Alternatively, breastfeeding may have a positive impact on pain symptoms, thus decreasing the likelihood of surgical evaluation for endometriosis among parous women.

Body size: Extensively studied, a consistent inverse association between adult BMI and endometriosis has been observed [14,36,39,44,55]. Additionally, women with a waist-to-hip ratio, a marker of body fat distribution, of $<0.60$ in the NHSII had almost a three-fold higher risk of endometriosis compared to women with a waist-to-hip ratio of $0.70-0.79(\mathrm{RR}=2.78,95 \%$ $\mathrm{CI}=1.38-5.60$ ) [40]. Similar results were observed in a case-control study [56] and may be explained by a genetic link, as the same intergenic locus on $7 \mathrm{p} 15.2$ was associated with endometriosis and body fat distribution (waist-to-hip ratio adjusted for BMI) [57]. Peripheral fat 
accumulation as opposed to visceral fat has been associated with a higher ratio of estrogens to androgens [58].

Physical activity: The relationship between physical activity and endometriosis has been inconsistent [59], potentially due to reverse causation from endometriosis symptoms affecting physical activity levels (Figure 4). In case-control studies relying on recalled physical activity levels, an approximately 40-80\% decreased risk of endometriosis has been observed with regular exercise $[43,44,60,61]$. However, a more modest, non-significant decreased risk of endometriosis comparing women with the highest physical activity levels to the lowest was observed in the NHSII (RR=0.89, 95\% CI=0.77-1.03) [62]. The prospective design of the NHSII overcomes limitations of recalled physical activity information inherent in case-control studies. Physical activity is known to influence hormone levels including lowering luteal estrogens [63] and increasing sex hormone binding globulin levels [64], which may potentially influence endometriosis development.

Dietary factors: There is limited literature on dietary factors and endometriosis risk, particularly among studies utilizing advanced nutritional epidemiologic methods. While no clear association has been observed between fish consumption and endometriosis in case-control studies, an inverse association was observed for intake of long-chain omega-3 fatty acid consumption and endometriosis in the NHSII $(\mathrm{RR}=0.88,95 \% \mathrm{CI}=0.62-0.99)$, with salad dressing as the primary source [65]. A similar inverse association was observed in a recent case-control study [66]. Women in the NHSII with the highest quintile of trans fat intake were at significantly greater risk 
of endometriosis diagnosis compared with women in the lowest quintile ( $R R=1.48,95 \%$ $\mathrm{CI}=1.17-1.88$ ) [65], although this finding was not replicated in a recent case-control study [67]. Trans-unsaturated fat intake may be related to the pathogenesis of endometriosis through the upregulation of inflammatory markers including IL-6 and markers of TNF system activation $[68,69]$. Conflicting results have been reported for fruit and vegetable intake $[67,70,71]$, red meat consumption, saturated fat and animal fat intake $[60,65-67,70,72]$, olive oil consumption and monounsaturated fat intake $[65,70,72]$, phytoestrogens and soy isoflavones $[73,74]$, dairy intake $[60,67,70,75]$, and serum vitamin D levels [76]. Variation in study design and nutritional epidemiologic methods may underlie this lack of replication. Future studies must account for diet temporality and total caloric intake, and apply substitution and other dietary component modeling methods.

Dermatologic and pigmentation characteristics: A positive dose-effect relation between risk of endometriosis and skin sensitivity $(\mathrm{OR}=1.22,95 \% \mathrm{CI}=1.10-1.36$ for highest vs. lowest tertile), number of moles $(\mathrm{OR}=1.59,95 \% \mathrm{CI}=1.37-1.83$ for highest vs. lowest quartile), and freckling $(\mathrm{OR}=1.11,95 \% \mathrm{CI}=1.03-1.20$ for highest vs. lowest tertile $)$ was reported in the $\mathrm{E} 3 \mathrm{~N}$ nested casecontrol study [77]. Similarly, endometriosis risk was associated with moles on the lower legs $(\mathrm{RR}=1.08,95 \% \mathrm{CI}=1.02-1.14)$ and a family history of melanoma $(\mathrm{RR}=1.13,95 \% \mathrm{CI}=1.01-1.26)$ within the NHSII [47]. Case-control studies have observed a higher risk of endometriosis among women with blue/green eyes [36,78]. Conflicting results have been reported for the association between red hair color and endometriosis risk $[47,77,79,80]$. 
Environmental toxins: Smarr et al. [81] recently summarized the evidence on endocrinedisrupting chemicals and endometriosis risk. Endocrine-disrupting chemicals, such as polychlorinated biphenyl (PCB) and dioxin, may influence endometriosis risk through the disruption of circulating hormone levels and/or dysregulation of the immune system [82]. However, the literature has been inconsistent, perhaps due to small sample sizes, varying time windows of exposure, and differences in control populations [81]. Two retrospective cohort studies have assessed the relationship between environmental toxins and endometriosis [20,83]. In the first study, women with levels of 2,3,7,8-tetrachlorodibenzo-p-dioxin (TCDD) >100 parts per trillion had a non-significant higher rate of endometriosis $(\mathrm{RR}=2.1,95 \% \mathrm{CI}=0.5-8.0)$ [83]. In the second study, women exposed to levels of PCBs $>8$ parts per billion had a greater but nonsignificant rate of endometriosis compared to women exposed to $\leq 5$ part per billion $(R R=1.68$, 95\% CI=0.95-2.98) [20].

Other Adulthood Exposures: Results for smoking and endometriosis risk have been conflicting, with some studies reporting an inverse association $[14,44,48]$, and others reporting no association $[14,43,50,84,85]$. This variation may be due in part to differences in risk between infertile and fertile women. In the NHSII, a positive association was observed among fertile women, while an inverse association was observed among infertile women [14]. While smokers have lower estrogen levels [31], they are also exposed to higher levels of exogenous estrogen from organochlorines. A greater risk of endometriosis has been noted for both alcohol and caffeine intake in infertile populations [60,86-88]. However, case-control studies of infertile and fertile women found no associations $[34,43,70,89]$. In the NHSII, no association was observed for caffeine intake and an inverse association was observed between alcohol and endometriosis 
[14]. A recent meta-analysis quantified no association between caffeine or coffee intake $(\mathrm{RR}=1.26 ; 95 \% \mathrm{CI}=0.95-1.66 ; \mathrm{RR}=1.13 ; 95 \% \mathrm{CI}=0.46-2.76$; respectively) [90]. Limited research has noted an association between night shift work and endometriosis risk [91,92]. Nightshift work has been shown to disrupt circadian estrogen secretion and has been associated with an elevated risk of other estrogen-dependent diseases, such as breast cancer [93,94]. 


\section{Potential Increased risk Potential Decreased risk \\ In-Utero and early life

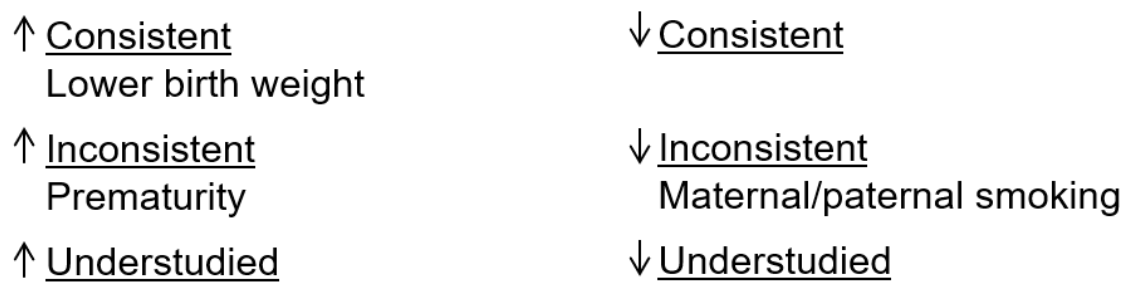 \\ Maternal diethylstilbestrol}

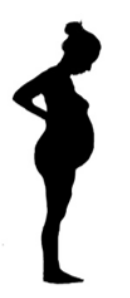

\section{Childhood and Adolescence}

$\uparrow \underline{\text { Consistent }}$

Earlier age at menarche Lower body mass index

$\uparrow \underline{\text { Inconsistent }}$

$\uparrow \underline{\text { Understudied }}$ Intense physical activity Passive smoke exposure Skin sensitivity

\section{Adulthood}

$\uparrow$ Consistent

Shorter menstrual cycle length Lower body mass index

$\uparrow \underline{\text { Inconsistent }}$ Greater height Alcohol use Caffeine intake PCB/dioxin exposure Red hair Freckling Moles Skin sensitivity

$\uparrow \underline{\text { Understudied }}$ Heavier menstrual volume Lower waist-to-hip ratio Night shift work Red meat/saturated fat Trans fat

\section{$\downarrow$ Consistent}

$\downarrow \underline{\text { Inconsistent }}$

$\downarrow \underline{\text { Understudied }}$

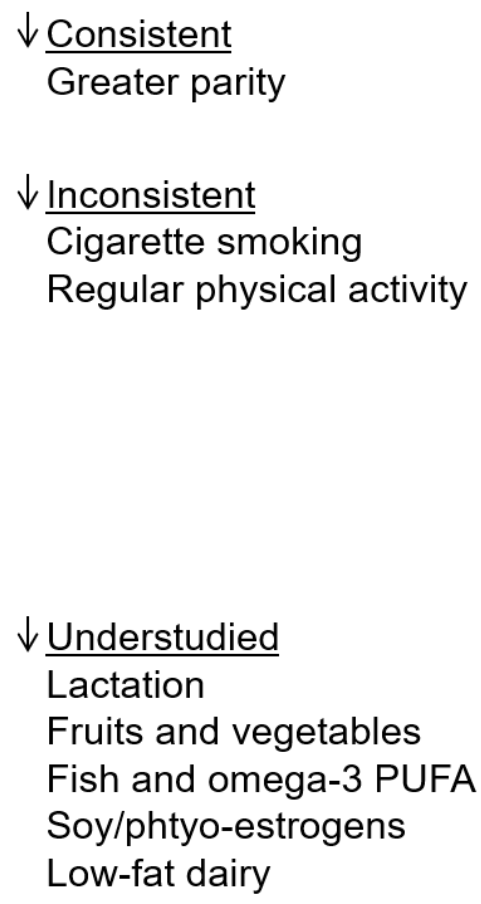

Figure 5. Risk factors for endometriosis 


\section{Endometriosis and Chronic Disease Risk}

A growing body of research suggests an association between endometriosis and other comorbid and chronic conditions $[95,96]$. However, the quality of the epidemiologic evidence, magnitude of association, and mechanism behind the association varies across different conditions. A key methodologic challenge is that women who are diagnosed with endometriosis may utilize treatments that alter their endometriosis disease (e.g. excision surgery) or that are directly related to other disease risk (e.g. exogenous hormones) or modify their lifestyle to address symptoms of endometriosis such as pain or infertility (e.g. dietary or physical activity alterations). Ideally these intermediate factors would be accounted for via formal mediation analytics. Women with endometriosis may, by the fact of their successful diagnosis, have greater access to healthcare and may also be more intensively screened than the general population, resulting in detection bias. Study design and analytic methods to address the potential impact of confounding, effect modification, mediation, bias, and reverse causation are therefore critical to incorporate when considering these associations.

Cancer: Among the most consistently demonstrated associations is that between endometriosis and clear cell and endometrioid ovarian cancer [95,97-99]. A pooled analysis of 13 ovarian cancer case-control studies reported an greater risk of clear cell $(\mathrm{OR}=3.05,95 \% \mathrm{CI}=2.43-3.84)$, low-grade serous $(\mathrm{OR}=2.11,95 \% \mathrm{CI}=1.39-3.20)$, and endometrioid ovarian cancers $(\mathrm{OR}=2.04$, 95\% $\mathrm{CI}=1.67-2.40)$ [97]. It is critical to determine if this elevated risk of ovarian cancer is associated with all phenotypes of endometriosis, or more precisely is driven primarily or solely by those with endometriomas [100,101]. Conversely, results have been conflicting for breast 
cancer, with some studies reporting a modest increased risk and others reporting a null or decreased risk associated with endometriosis [95,102-104]. Breast cancer is heterogeneous in the timing of disease onset (before or after menopause), tumor hormone receptor status, and molecular subtypes, and few studies have investigated these differences [104], with the vast majority of studies investigating all breast cancers as a single outcome. Thus, some of the conflicting results may be caused by true variation in the association by breast cancer subtype.

There has been relatively limited research into the association between endometriosis and other reproductive cancers. The majority of research has suggested no association between endometriosis and endometrial cancer [95,100,105]; however, two studies reported a positive association and one study reported an inverse association [95]. While studies investigating the association between endometriosis and cervical cancer are limited, they have consistently reported an inverse association between the two conditions [95].

Seven studies investigating endometriosis and skin cancer have reported an association between endometriosis and cutaneous melanoma, although five studies have reported no association $[95,106]$. Very few studies have focused on non-melanoma skin cancers and suggest either a very modest or no association $[95,106]$.

Cardiovascular conditions: Prospective data from the NHSII has suggested an association between endometriosis and cardiovascular conditions [107]. Endometriosis was associated with a 
greater risk of cardiovascular disease (myocardial infarction, angiographically-confirmed angina, coronary artery bypass graft $)(\mathrm{RR}=1.62,95 \% \mathrm{CI}=1.39-1.89)$. About $50 \%$ of the association was attributed to the high rate of hysterectomy/oophorectomy among women with endometriosis. Limited research has also shown a greater risk of hypertension [108], hypercholesterolemia [108-110], and subclinical atherosclerosis [111] among women with endometriosis.

Immune system diseases: Research is limited with regards to endometriosis and autoimmune conditions. Some studies have suggested a higher risk of systemic lupus erythematosus, multiple sclerosis, rheumatoid arthritis, and Sjögren's syndrome among women diagnosed with endometriosis [112-116]; however, other studies reported no association [21,84,117].

\section{Summary}

While estimates of endometriosis prevalence and incidence are difficult to calculate due to the absence of a non-invasive diagnostic method, the best estimates conclude that approximately $10 \%$ of reproductive aged women are afflicted with endometriosis. Methodologic complexity associated with this disease requires application of advanced study design and statistical methodology. Many different case definitions can be utilized validly and the type of women included in comparison/control groups can vary based upon the study aims. These details are important to describe and take into account when comparing and contrasting studies.

The long delay between endometriosis symptom onset and diagnosis can lead to reverse causation, particularly for modifiable risk factors and studies based on recalled exposure 
information. Overall, a greater risk of endometriosis has been consistently reported for earlier age at menarche, shorter menstrual cycle length, and lean BMI, while a lower risk has been consistently associated with greater parity. Conflicting results have been observed for physical activity both in childhood and adulthood, dietary factors, environmental toxins, lactation, night shift work, and cigarette smoking. Further research is needed into early life, childhood and adolescent exposures as risk factor profiles may differ between women diagnosed during adolescence and women diagnosed in adulthood. The phenotypic variation among women with endometriosis must be embraced, defined, and explored. Excellence in methodologic design and requirement for replication are vital to advance our understanding of risk factors for and consequences of endometriosis.

\section{Conflict of Interest}

Conflicts of interest: No funding directly supported development or finalization of this manuscript.

S.A.M. received grant funding from the US National Institutes of Health (NIH; HD40882, HD48544, HD52473, HD57210, HD089511), the J.Willard and Alice S. Marriott Foundation and the Marriott Daughters' Foundation, and the Dana-Farber/Harvard Cancer Center (DF/HCC) A. David Mazzone Research Awards Program for endometriosis-associated aims. She has served as an advisor to and has scientific collaborations with AbbVie Inc, Celmatix, and Oratel Diagnostics. She is a Treasurer of the World Endometriosis Society (WES), Secretary of the World Endometriosis Research Foundation (WERF), America; Chair of the American Society for Reproductive Medicine (ASRM) Endometriosis Special Interest Group 
(EndoSIG), and member of the NIH Reproductive Medicine Network (RMN) Data Safety and Monitoring Board (DSMB).

K.T.Z. has received grant funding from the Wellcome Trust, Medical Research Council UK, the US National Institutes of Health $(\mathrm{NIH})$, the European Union, and the World Endometriosis Research Foundation. She also has scientific collaborations with, and received grant funding from, Bayer AG, Roche Diagnostics, Volition Rx, MDNA Life Sciences, and has served as a scientific consultant to AbbVie Inc, Roche Diagnostics. She is Secretary of the World Endometriosis Society (WES), the ESHRE Special Interest Group in Endometriosis and Endometrial Disorders, and of Wellbeing of Women UK; and Chair of the WES Research Directions Working Group.

H.R.H. is supported by the National Cancer Institute, NIH (K22 CA193860). 


\section{Research agenda}

Determine the true prevalence and incidence of endometriosis

Define informative subtypes of endometriosis to advance discovery of etiologic pathways personalized diagnostics and treatment

Determine the natural history of the disease to better define critical windows of exposure

Identify high risk groups for co-morbidities and chronic disease among women with

endometriosis 


\section{References (10 most important marked with *)}

[1] Moen MH, Schei B. Epidemiology of endometriosis in a Norwegian county. Acta Obs Gynecol Scand 1997;76:559-62.

[2] Strathy JH, Molgaard CA, Coulam CB, Melton 3rd LJ. Endometriosis and infertility: a laparoscopic study of endometriosis among fertile and infertile women. Fertil Steril 1982;38:667-72.

[3] Flores I, Abreu S, Abac S, Fourquet J, Laboy J, Ríos-Bedoya C. Self-reported prevalence of endometriosis and its symptoms among Puerto Rican women. Int J Gynecol Obstet 2008;100:257-61. doi:10.1016/j.ijgo.2007.08.010.

[4] Duignan NM, Jordan JA, Coughlan BM, Logan-Edwards R. One thousand consecutive cases of diagnostic laparoscopy. J Obs Gynaecol Br Commonw 1972;79:1016-24.

[5] Liston WA, Bradford WP, Downie J, Kerr MG. Laparoscopy in a general gynecologic unit. Am J Obs Gynecol 1972;113:672-7. doi:0002-9378(72)90636-9 [pii].

[6] Kleppinger RK. One thousand laparoscopies at a community hospital. J Reprod Med $1974 ; 13: 13-20$.

[7] Hasson HM. Incidence of endometriosis in diagnostic laparoscopy. J Reprod Med 1976;16:135-8.

[8] Meuleman C, Vandenabeele B, Fieuws S, Spiessens C, Timmerman D, D’Hooghe T. High prevalence of endometriosis in infertile women with normal ovulation and normospermic partners. Fertil Steril 2009;92:68-74. doi:S0015-0282(08)00975-8 [pii]10.1016/j.fertnstert.2008.04.056 [doi].

*[9] Buck Louis GM, Hediger ML, Peterson CM, Croughan M, Sundaram R, Stanford J, et al. Incidence of endometriosis by study population and diagnostic method: the ENDO study. 
Fertil Steril 2011;96:360-5. doi:S0015-0282(11)00873-9 [pii]

10.1016/j.fertnstert.2011.05.087 [doi].

*[10] Zondervan KT, Cardon LR, Kennedy SH. What makes a good case-control study? Design issues for complex traits such as endometriosis. Hum Reprod 2002;17:1415-23.

[11] Janssen EB, Rijkers AC, Hoppenbrouwers K, Meuleman C, D'Hooghe TM. Prevalence of endometriosis diagnosed by laparoscopy in adolescents with dysmenorrhea or chronic pelvic pain: a systematic review. Hum Reprod Updat 2013;19:570-82. doi:dmt016 [pii] 10.1093/humupd/dmt016 [doi].

*[12] Houston DE, Noller KL, Melton 3rd LJ, Selwyn BJ, Hardy RJ. Incidence of pelvic endometriosis in Rochester, Minnesota, 1970-1979. Am J Epidemiol 1987;125:959-69.

[13] Leibson CL, Good AE, Hass SL, Ransom J, Yawn BP, O'Fallon WM, et al. Incidence and characterization of diagnosed endometriosis in a geographically defined population. Fertil Steril 2004;82:314-21. doi:10.1016/j.fertnstert.2004.01.037 S0015028204008623 [pii].

*[14] Missmer SA, Hankinson SE, Spiegelman D, Barbieri RL, Marshall LM, Hunter DJ. Incidence of laparoscopically confirmed endometriosis by demographic, anthropometric, and lifestyle factors. Am J Epidemiol 2004;160:784-96. doi:160/8/784 [pii] 10.1093/aje/kwh275 [doi].

[15] Missmer SA, Cramer DW. The epidemiology of endometriosis. Obs Gynecol Clin North Am 2003;30:1-19.

[16] Holt VL, Weiss NS. Recommendations for the design of epidemiologic studies of endometriosis. Epidemiology 2000;11:654-9.

[17] Vercellini P, Somigliana E, Cortinovis I, Bracco B, de Braud L, Dridi D, et al. "You can't always get what you want": from doctrine to practicability of study designs for clinical 
investigation in endometriosis. BMC Womens Heal 2015;15:89. doi:10.1186/s12905-015$0248-4$.

*[18] Pardanani S, Barbieri RL. The gold standard for the surgical diagnosis of endometriosis: visual findings or biopsy results. J Gyn Tech 1998;4:121-4.

[19] Duleba AJ. Diagnosis of endometriosis. Obs Gynecol Clin North Am 1997;24:331-46.

[20] Hoffman CS, Small CM, Blanck HM, Tolbert P, Rubin C, Marcus M. Endometriosis among women exposed to polybrominated biphenyls. Ann Epidemiol 2007;17:503-10. doi:S1047-2797(07)00057-9 [pii] 10.1016/j.annepidem.2006.11.005.

*[21] Nnoaham KE, Hummelshoj L, Webster P, D’Hooghe T, de Cicco Nardone F, De Cicco Nardone $\mathrm{C}$, et al. Impact of endometriosis on quality of life and work productivity: a multicenter study across ten countries. Fertil Steril 2011;96:366-373 e8. doi:S00150282(11)00876-4 [pii] 10.1016/j.fertnstert.2011.05.090 [doi].

[22] Farland L V, Missmer SA, Rich-Edwards J, Chavarro JE, Barbieri RL, Grodstein F. Use of fertility treatment modalities in a large United States cohort of professional women. Fertil Steril 2014;101:1705-10. doi:S0015-0282(14)00257-X [pii] 10.1016/j.fertnstert.2014.03.016 [doi].

[23] Farland L V., Collier ARY, Correia KF, Grodstein F, Chavarro JE, Rich-Edwards J, et al. Who receives a medical evaluation for infertility in the United States? Fertil Steril 2016;105:1274-80. doi:10.1016/j.fertnstert.2015.12.132.

[24] Vercellini P, Fedele L, Aimi G, De Giorgi O, Consonni D, Crosignani PG. Reproductive performance, pain recurrence and disease relapse after conservative surgical treatment for endometriosis: The predictive value of the current classification system. Hum Reprod 2006;21:2679-85. doi:10.1093/humrep/del230. 
*[25] Becker CM, Laufer MR, Stratton P, Hummelshoj L, Missmer SA, Zondervan KT, et al. World Endometriosis Research Foundation Endometriosis Phenome and Biobanking Harmonisation Project: I. Surgical phenotype data collection in endometriosis research. Fertil Steril 2014;102:1213-22. doi:10.1016/j.fertnstert.2014.07.709.

[26] Missmer SA, Hankinson SE, Spiegelman D, Barbieri RL, Michels KB, Hunter DJ. In utero exposures and the incidence of endometriosis. Fertil Steril 2004;82:1501-8. doi:S0015-0282(04)02351-9 [pii]10.1016/j.fertnstert.2004.04.065 [doi].

[27] Upson K, Sathyanarayana S, Scholes D, Holt VL. Early-life factors and endometriosis risk. Fertil Steril 2015;104:964-971e5. doi:10.1016/j.fertnstert.2015.06.040.

[28] Newbold R. Cellular and Molecular Effects of Developmental Exposure to Diethylsti bestrol: Implications for Other Environmental Estrogens. Env Heal Perspect 1995;103:837.

[29] Wolff EF, Sun L, Hediger ML, Sundaram R, Peterson CM, Chen Z, et al. In utero exposures and endometriosis: the Endometriosis, Natural History, Disease, Outcome (ENDO) Study. Fertil Steril 2013;99:790-5. doi:S0015-0282(12)02408-9 [pii] 10.1016/j.fertnstert.2012.11.013 [doi].

[30] Buck Louis GM, Hediger ML, Pena JB. Intrauterine exposures and risk of endometriosis. Hum Reprod 2007;22:3232-6. doi:dem338 [pii] 10.1093/humrep/dem338.

[31] Baron JA, La Vecchia C, Levi F. The antiestrogenic effect of cigarette smoking in women. Am J Obs Gynecol 1990;162:502-14.

[32] Vannuccini S, Lazzeri L, Orlandini C, Tosti C, Clifton VL, Petraglia F. Potential influence of in utero and early neonatal exposures on the later development of endometriosis. Fertil Steril 2016;105:997-1002. doi:10.1016/j.fertnstert.2015.12.127. 
[33] Missmer SA, Hankinson SE, Spiegelman D, Barbieri RL, Malspeis S, Willett WC, et al. Reproductive history and endometriosis among premenopausal women. Obs Gynecol 2004;104:965-74. doi:104/5/965 [pii] 10.1097/01.AOG.0000142714.54857.f8 [doi].

[34] Matalliotakis IM, Cakmak H, Fragouli YG, Goumenou AG, Mahutte NG, Arici A. Epidemiological characteristics in women with and without endometriosis in the Yale series. Arch Gynecol Obstet 2008;277:389-93. doi:10.1007/s00404-007-0479-1.

[35] Nnoaham KE, Webster P, Kumbang J, Kennedy SH, Zondervan KT. Is early age at menarche a risk factor for endometriosis? A systematic review and meta-analysis of casecontrol studies. Fertil Steril 2012;98:702-712 e6. doi:S0015-0282(12)00589-4 [pii] 10.1016/j.fertnstert.2012.05.035 [doi].

[36] Vigano P, Somigliana E, Panina P, Rabellotti E, Vercellini P, Candiani M. Principles of phenomics in endometriosis. Hum Reprod Updat 2012;18:248-59. doi:dms001 [pii]10.1093/humupd/dms001 [doi].

[37] Hediger ML, Hartnett HJ, Louis GM. Association of endometriosis with body size and figure. Fertil Steril 2005;84:1366-74. doi:S0015-0282(05)02774-3 [pii] 10.1016/j.fertnstert.2005.05.029 [doi].

[38] Vitonis AF, Baer HJ, Hankinson SE, Laufer MR, Missmer SA. A prospective study of body size during childhood and early adulthood and the incidence of endometriosis. Hum Reprod 2010;25:1325-34. doi:deq039 [pii] 10.1093/humrep/deq039 [doi].

[39] Farland LV, Missmer SA, Bijon A, Gusto G, Gelot A, Clavel-Chapelon F, et al. Associations among body size across the life course, adult height and endometriosis. Hum Reprod 2017;32:1732-42. doi:10.1093/humrep/dex207.

[40] Shah DK, Correia KF, Vitonis AF, Missmer SA. Body size and endometriosis: results 
from 20 years of follow-up within the Nurses' Health Study II prospective cohort. Hum Reprod 2013;28:1783-92. doi:det120 [pii] 10.1093/humrep/det120 [doi].

[41] Sorensen T, Stunkard A, Teasdale T, Higgins M. The accuracy of reports of weight: children's recall of their parents' weights 15 years earlier. Int J Obes 1983;7:115-22.

[42] Yi KW, Shin JH, Park MS, Kim T, Kim SH, Hur JY. Association of body mass index with severity of endometriosis in Korean women. Int J Gynaecol Obs 2009;105:39-42. doi:S0020-7292(08)00504-3 [pii] 10.1016/j.ijgo.2008.11.001 [doi].

[43] Signorello LB, Harlow BL, Cramer DW, Spiegelman D, Hill JA. Epidemiologic determinants of endometriosis: a hospital-based case-control study. Ann Epidemiol 1997;7:267-741. doi:S1047-2797(97)00017-3 [pii].

[44] Cramer DW, Wilson E, Stillman RJ, Berger MJ, Belisle S, Schiff I, et al. The relation of endometriosis to menstrual characteristics, smoking, and exercise. JAMA 1986;255:19048.

[45] Kvaskoff M, Bijon A, Clavel-Chapelon F, Mesrine S, Boutron-Ruault MC. Childhood and adolescent exposures and the risk of endometriosis. Epidemiology 2013;24:261-9. doi:10.1097/EDE.0b013e3182806445 [doi].

[46] Vitonis AF, Maruti SS, Hankinson SE, Hornstein MD, Missmer SA. Adolescent physical activity and endometriosis risk. J Endometr 2009;1:157-63. doi:10.1007/s11103-0119767-z.Plastid.

[47] Kvaskoff M, Han J, Qureshi AA, Missmer SA. Pigmentary traits, family history of melanoma and the risk of endometriosis: a cohort study of US women. Int J Epidemiol 2014;43:255-63. doi:dyt235 [pii] 10.1093/ije/dyt235 [doi].

[48] Darrow SL, Vena JE, Batt RE, Zielezny MA, Michalek AM, Selman S. Menstrual cycle 
characteristics and the risk of endometriosis. Epidemiology 1993;4:135-42.

[49] Parazzini F, Ferraroni M, Fedele L, Bocciolone L, Rubessa S, Riccardi A. Pelvic endometriosis: reproductive and menstrual risk factors at different stages in Lombardy, northern Italy. J Epidemiol Community Heal 1995;49:61-4.

[50] Sangi-Haghpeykar H, Poindexter 3rd AN. Epidemiology of endometriosis among parous women. Obs Gynecol 1995;85:983-92. doi:0029-7844(95)00074-2 [pii] 10.1016/00297844(95)00074-2.

*[51] Peterson CM, Johnstone EB, Hammoud AO, Stanford JB, Varner MW, Kennedy A, et al. Risk factors associated with endometriosis: importance of study population for characterizing disease in the ENDO Study. Am J Obs Gynecol 2013;208:451.e1-451.11. doi:10.1016/j.ajog.2013.02.040.Risk.

[52] Prescott J, Farland L V., Tobias DK, Gaskins AJ, Spiegelman D, Chavarro JE, et al. A prospective cohort study of endometriosis and subsequent risk of infertility. Hum Reprod 2016;31:1475-82. doi:dew085 [pii]10.1093/humrep/dew085 [doi].

[53] Buck Louis GM, Backonja U, Schliep KKC, Sun L, Peterson CM, Chen Z. Women's Reproductive History Before the Diagnosis of Incident Endometriosis. J Women's Heal 2016;25:1021-9. doi:10.1089/jwh.2015.5712.

[54] Farland L V, Eliassen AH, Tamimi RM, Spiegelman D, Michels KB, Missmer SA. History of breast feeding and risk of incident endometriosis: prospective cohort study. Bmj 2017;358:j3778. doi:10.1136/bmj.j3778.

[55] Liu Y, Zhang W. Association between body mass index and endometriosis risk: a metaanalysis. Oncotarget 2017;8:46928-36. doi:10.18632/oncotarget.14916.

[56] McCann SE, Freudenheim JL, Darrow SL, Batt RE, Zielezny MA. Endometriosis and 
body fat distribution. Obs Gynecol 1993;82:545-9.

[57] Rahmioglu N, Nyholt DR, Morris AP, Missmer SA, Montgomery GW, Zondervan KT. Genetic variants underlying risk of endometriosis: insights from meta-analysis of eight genome-wide association and replication datasets. Hum Reprod Updat 2014;20:702-16. doi:dmu015 [pii]10.1093/humupd/dmu015 [doi].

[58] de Ridder CM, Bruning PF, Zonderland ML, Thijssen JH, Bonfrer JM, Blankenstein MA, et al. Body fat mass, body fat distribution, and plasma hormones in early puberty in females. J Clin Endocrinol Metab 1990;70:888-93. doi:10.1210/jcem-70-4-888 [doi].

[59] Ricci E, Vigano P, Cipriani S, Chiaffarino F, Bianchi S, Rebonato G, et al. Physical activity and endometriosis risk in women with infertility or pain: Systematic review and meta-analysis. Med 2016;95:e4957. doi:10.1097/md.0000000000004957.

[60] Heilier JF, Donnez J, Nackers F, Rousseau R, Verougstraete V, Rosenkranz K, et al. Environmental and host-associated risk factors in endometriosis and deep endometriotic nodules: a matched case-control study. Env Res 2007;103:121-9. doi:S00139351(06)00077-6 [pii] 10.1016/j.envres.2006.04.004.

[61] Dhillon PK, Holt VL. Recreational physical activity and endometrioma risk. Am J Epidemiol 2003;158:156-64.

[62] Vitonis AF, Hankinson SE, Hornstein MD, Missmer SA. Adult physical activity and endometriosis risk. Epidemiology 2010;21:16-23. doi:10.1097/EDE.0b013e3181c15d40.Adult.

[63] Tworoger SS, Missmer SA, Eliassen AH, Barbieri RL, Dowsett M, Hankinson SE. Physical activity and inactivity in relation to sex hormone, prolactin, and insulin-like growth factor concentrations in premenopausal women - exercise and premenopausal 
hormones. Cancer Causes Control 2007;18:743-52. doi:10.1007/s10552-007-9017-5.

[64] An P, Rice T, Gagnon J, Hong Y, Leon AS, Skinner JS, et al. A genetic study of sex hormone--binding globulin measured before and after a 20-week endurance exercise training program: the HERITAGE Family Study. Metabolism 2000;49:1014-20. doi:S0026-0495(00)47739-5 [pii] 10.1053/meta.2000.7737.

[65] Missmer SA, Chavarro JE, Malspeis S, Bertone-Johnson ER, Hornstein MD, Spiegelman D, et al. A prospective study of dietary fat consumption and endometriosis risk. Hum Reprod 2010;25:1528-35. doi:deq044 [pii] 10.1093/humrep/deq044 [doi].

[66] Savaris AL, do Amaral VF. Nutrient intake, anthropometric data and correlations with the systemic antioxidant capacity of women with pelvic endometriosis. Eur J Obs Gynecol Reprod Biol 2011;158:314-8. doi:S0301-2115(11)00306-X [pii] 10.1016/j.ejogrb.2011.05.014 [doi].

[67] Trabert B, Peters U, De Roos AJ, Scholes D, Holt VL. Diet and risk of endometriosis in a population-based case-control study. Br J Nutr 2011;105:459-67. doi:S0007114510003661 [pii] 10.1017/S0007114510003661 [doi].

[68] Lebovic DI, Mueller MD, Taylor RN. Immunobiology of endometriosis. Fertil Steril 2001;75:1-10. doi:S0015-0282(00)01630-7 [pii].

[69] Mozaffarian D, Pischon T, Hankinson SE, Rifai N, Joshipura K, Willett WC, et al. Dietary intake of trans fatty acids and systemic inflammation in women. Am J Clin Nutr 2004;79:606-12.

[70] Parazzini F, Chiaffarino F, Surace M, Chatenoud L, Cipriani S, Chiantera V, et al. Selected food intake and risk of endometriosis. Hum Reprod 2004;19:1755-9. doi:10.1093/humrep/deh395 deh395 [pii]. 
[71] Harris HR, Eke AC, Chavarro JE, Missmer SA. Fruit and vegetable consumption and risk of endometriosis. Hum Reprod 2018;33:715-27. doi:10.1093/humrep/dey014.

[72] Britton JA, Westhoff C, Howe G, Gammon MD. Diet and benign ovarian tumors (United States). Cancer Causes Control 2000;11:389-401.

[73] Tsuchiya M, Miura T, Hanaoka T, Iwasaki M, Sasaki H, Tanaka T, et al. Effect of soy isoflavones on endometriosis: interaction with estrogen receptor 2 gene polymorphism. Epidemiology 2007;18:402-8.

[74] Mumford SL, Weck J, Kannan K, Buck Louis GM. Urinary Phytoestrogen Concentrations Are Not Associated with Incident Endometriosis in Premenopausal Women. J Nutr 2017;147:227-34. doi:10.3945/jn.116.238840.

[75] Harris HR, Chavarro JE, Malspeis S, Willett WC, Missmer SA. Dairy-food, calcium, magnesium, and vitamin D intake and endometriosis: A prospective cohort study. Am J Epidemiol 2013;177:420-30. doi:10.1093/aje/kws247.

[76] Buggio L, Roncella E, Somigliana E, Vercellini P. Vitamin D and benign gynaecological diseases: a critical analysis of the current evidence. Gynecol Endocrinol 2016;32:259-63. doi:10.3109/09513590.2015.1111329.

[77] Kvaskoff M, Mesrine S, Clavel-Chapelon F, Boutron-Ruault MC. Endometriosis risk in relation to naevi, freckles and skin sensitivity to sun exposure: the French E3N cohort. Int J Epidemiol 2009;38:1143-53. doi:dyp175 [pii] 10.1093/ije/dyp175.

[78] Somigliana E, Vigano P, Abbiati A, Gentilini D, Parazzini F, Benaglia L, et al. "Here comes the sun": pigmentary traits and sun habits in women with endometriosis. Hum Reprod 2010;25:728-33. doi:dep453 [pii] 10.1093/humrep/dep453 [doi].

[79] Missmer SA, Spiegelman D, Hankinson SE, Malspeis S, Barbieri RL, Hunter DJ. Natural 
hair color and the incidence of endometriosis. Fertil Steril 2006;85:866-70. doi:S00150282(05)04323-2 [pii] 10.1016/j.fertnstert.2005.12.008 [doi].

[80] Wyshak G, Frisch RE. Red hair color, melanoma, and endometriosis: suggestive associations. Int J Dermatol 2000;39:798.

*[81] Smarr MM, Kannan K, Buck Louis GM. Endocrine disrupting chemicals and endometriosis. Fertil Steril 2016;106:959-66. doi:10.1016/j.fertnstert.2016.06.034.

[82] Rier SE, Martin DC, Bowman RE, Dmowski WP, Becker JL. Endometriosis in rhesus monkeys (Macaca mulatta) following chronic exposure to 2,3,7,8-tetrachlorodibenzo-pdioxin. Fundam Appl Toxicol 1993;21:433-41. doi:S027205908371119X [pii].

[83] Eskenazi B, Mocarelli P, Warner M, Samuels S, Vercellini P, Olive D, et al. Serum dioxin concentrations and endometriosis: a cohort study in Seveso, Italy. Env Heal Perspect 2002;110:629-34. doi:sc271_5_1835 [pii].

[84] Matorras R, Rodiquez F, Pijoan JI, Ramon O, Gutierrez de Teran G, Rodriguez-Escudero F. Epidemiology of endometriosis in infertile women. Fertil Steril 1995;63:34-8.

[85] Vessey MP, Villard-Mackintosh L, Painter R. Epidemiology of endometriosis in women attending family planning clinics. BMJ 1993;306:182-4.

[86] Berube S, Marcoux S, Maheux R. Characteristics related to the prevalence of minimal or mild endometriosis in infertile women. Canadian Collaborative Group on Endometriosis. Epidemiology 1998;9:504-10.

[87] Grodstein F, Goldman MB, Ryan L, Cramer DW. Relation of female infertility to consumption of caffeinated beverages. Am J Epidemiol 1993;137:1353-60.

[88] Grodstein F, Goldman MB, Cramer DW. Infertility in women and moderate alcohol use. Am J Public Heal 1994;84:1429-32. 
[89] Hemmings R, Rivard M, Olive DL, Poliquin-Fleury J, Gagne D, Hugo P, et al. Evaluation of risk factors associated with endometriosis. Fertil Steril 2004;81:1513-21. doi:10.1016/j.fertnstert.2003.10.038 S001502820400216X [pii].

[90] Chiaffarino F, Bravi F, Cipriani S, Parazzini F, Ricci E, Viganò P, et al. Coffee and caffeine intake and risk of endometriosis: a meta-analysis. Eur J Nutr 2014;53:1573-9. doi:10.1007/s00394-014-0662-7.

[91] Marino JL, Holt VL, Chen C, Davis S. Shift work, hCLOCK T3111C polymorphism, and endometriosis risk. Epidemiology 2008;19:477-84. doi:10.1097/EDE.0b013e31816b7378.

[92] Schernhammer ES, Vitonis AF, Rich-Edwards J, Missmer SA. Rotating nightshift work and the risk of endometriosis in premenopausal women. Am J Obs Gynecol 2011;205:476 e1-8. doi:S0002-9378(11)00730-7 [pii] 10.1016/j.ajog.2011.06.002 [doi].

[93] Schernhammer ES, Laden F, Speizer FE, Willett WC, Hunter DJ, Kawachi I, et al. Rotating night shifts and risk of breast cancer in women participating in the nurses' health study. J Natl Cancer Inst 2001;93:1563-8.

[94] Hansen J. Increased breast cancer risk among women who work predominantly at night. Epidemiology 2001;12:74-7.

*[95] Kvaskoff M, Mu F, Terry KL, Harris HR, Poole EM, Farland L, et al. Endometriosis: a high-risk population for major chronic diseases? Hum Reprod Update 2015;21:500-16. doi:dmv013 [pii] 10.1093/humupd/dmv013 [doi].

[96] Parazzini F, Esposito G, Tozzi L, Noli S, Bianchi S. Epidemiology of endometriosis and its comorbidities. Eur J Obstet Gynecol Reprod Biol 2017;209:3-7.

[97] Pearce CL, Templeman C, Rossing MA, Lee A, Near AM, Webb PM, et al. Association between endometriosis and risk of histological subtypes of ovarian cancer: a pooled 
analysis of case-control studies. Lancet Oncol 2012;13:385-94. doi:S1470-

2045(11)70404-1 [pii]10.1016/S1470-2045(11)70404-1.

[98] Kim HS, Kim TH, Chung HH, Song YS. Risk and prognosis of ovarian cancer in women with endometriosis: a meta-analysis. Br J Cancer 2014;110:1878-90. doi:bjc201429 [pii]10.1038/bjc.2014.29 [doi].

[99] Wang C, Liang Z, Liu X, Zhang Q, Li S. The association between endometriosis, tubal ligation, hysterectomy and epithelial ovarian cancer: Meta-analyses. Int J Environ Res Public Health 2016;13. doi:10.3390/ijerph13111138.

[100] Saavalainen L, Lassus H, But A, Tiitinen A, Härkki P, Gissler M, et al. Risk of Gynecologic Cancer According to the Type of Endometriosis. Obstet Gynecol 2018:[Epub ahead of print]. doi:10.1097/AOG.0000000000002624.

[101] Kvaskoff M, Horne AW, Missmer SA. Informing women with endometriosis about ovarian cancer risk. Lancet 2017;390:2433-4. doi:10.1016/S0140-6736(17)33049-0.

[102] Kok VC, Tsai HJ, Su CF, Lee CK. The Risks for Ovarian, Endometrial, Breast, Colorectal, and Other Cancers in Women With Newly Diagnosed Endometriosis or Adenomyosis: A Population-Based Study. Int J Gynecol Cancer 2015;25:968-76. doi:10.1097/IGC.0000000000000454 [doi].

[103] Nichols HB, Visvanathan K, Newcomb PA, Hampton JM, Egan KM, Titus-Ernstoff L, et al. Bilateral oophorectomy in relation to risk of postmenopausal breast cancer: confounding by nonmalignant indications for surgery? Am J Epidemiol 2011;173:111120. doi:kwq510 [pii]10.1093/aje/kwq510 [doi].

[104] Farland L V, Tamimi RM, Eliassen AH, Spiegelman D, Hankinson SE, Chen WY, et al. Laparoscopically Confirmed Endometriosis and Breast Cancer in the Nurses' Health 
Study II. Obs Gynecol 2016;128:1025-31. doi:10.1097/aog.0000000000001684.

[105] Poole EM, Lin WT, Kvaskoff M, De Vivo I, Terry KL, Missmer SA. Endometriosis and risk of ovarian and endometrial cancers in a large prospective cohort of U.S. nurses. Cancer Causes Control 2017;28:437-45. doi:10.1007/s10552-017-0856-4.

[106] Farland L V., Lorrain S, Missmer SA, Dartois L, Cervenka I, Savoye I, et al. Endometriosis and the risk of skin cancer: a prospective cohort study. Cancer Causes Control 2017. doi:10.1007/s10552-017-0939-2.

[107] Mu F, Rich-Edwards J, Rimm EB, Spiegelman D, Missmer SA. Endometriosis and Risk of Coronary Heart Disease. Circ Cardiovasc Qual Outcomes 2016;9:257-64. doi:10.1161/circoutcomes.115.002224.

[108] Mu F, Rich-Edwards J, Rimm EB, Spiegelman D, Forman JP, Missmer SA. Association Between Endometriosis and Hypercholesterolemia or Hypertension. Hypertension 2017;70:59-65. doi:10.1161/HYPERTENSIONAHA.117.09056.

[109] Verit FF, Erel O, Celik N. Serum paraoxonase-1 activity in women with endometriosis and its relationship with the stage of the disease. Hum Reprod 2008;23:100-4. doi:10.1093/humrep/dem340.

[110] Melo AS, Rosa-E-Silva JC, De Sá Rosa-E-Silva ACJ, Poli-Neto OB, Ferriani RA, Vieira CS. Unfavorable lipid profile in women with endometriosis. Fertil Steril 2010;93:2433-6. doi:10.1016/j.fertnstert.2009.08.043.

[111] Pretta S, Remorgida V, Abbamonte LH, Anserini P, Ragni N, Del Sette M, et al. Atherosclerosis in women with endometriosis. Eur J Obstet Gynecol Reprod Biol 2007;132:226-31. doi:10.1016/j.ejogrb.2006.04.015.

[112] Sinaii N, Cleary SD, Ballweg ML, Nieman LK, Stratton P. High rates of autoimmune and 
endocrine disorders, fibromyalgia, chronic fatigue syndrome and atopic diseases among women with endometriosis: a survey analysis. Hum Reprod 2002;17:2715-24.

[113] Harris HR, Costenbader KH, Mu F, Kvaskoff M, Malspeis S, Karlson EW, et al. Endometriosis and the risks of systemic lupus erythematosus and rheumatoid arthritis in the Nurses’ Health Study II. Ann Rheum Dis 2016;75:1279-84.

doi:10.1136/annrheumdis-2015-207704.

[114] Nielsen NM, Jorgensen KT, Pedersen B V, Rostgaard K, Frisch M. The co-occurrence of endometriosis with multiple sclerosis, systemic lupus erythematosus and Sjogren syndrome. Hum Reprod 2011;26:1555-9. doi:der105 [pii]10.1093/humrep/der105.

[115] Caserta D, Mallozzi M, Pulcinelli F, Mossa B, Moscarini M. Endometriosis allergic or autoimmune disease: pathogenetic aspects--a case control study. Clin Exp Obs Gynecol $2016 ; 43: 354-7$.

[116] Harris HR, Simard JF, Arkema E V. Endometriosis and systemic lupus erythematosus: A population-based case-control study. Lupus 2016;25:1045-9. doi:10.1177/0961203316631635.

[117] Petta CA, Arruda MS, Zantut-Wittmann DE, Benetti-Pinto CL. Thyroid autoimmunity and thyroid dysfunction in women with endometriosis. Hum Reprod 2007;22:2693-7. doi:10.1093/humrep/dem267. 